\title{
Inoculação micorrízica e aclimatização de dois porta-enxertos de macieira micropropagados(1)
}

\author{
Lucir Maria Locatelli(2) e Paulo Emílio Lovato(3)
}

\begin{abstract}
Resumo - A micropropagação e a inoculação de fungos micorrízicos arbusculares (FMA) podem melhorar a qualidade de mudas produzidas comercialmente. Essas técnicas permitem a produção de plantas homogêneas e de alta qualidade em curtos períodos de tempo, mas isso exige o conhecimento da interação entre fungos e plantas, substratos e técnicas de aclimatização e inoculação. Foi realizado um estudo em condições controladas a fim de desenvolver procedimentos para aclimatizar e inocular FMA nos porta-enxertos de macieira (Malus spp.) Marubakaido, vigoroso e com forte sistema radicular, e M.9, nanizante e com sistema radicular pouco desenvolvido. Plantas oriundas de micropropagação foram imersas em ácido indolebutírico $(5 \mu \mathrm{M})$ e transferidas para substrato à base de solo, a fim de serem enraizadas ex vitro. Antes ou após o enraizamento, inoculou-se uma mistura de isolados de Scutellospora pellucida, Glomus etunicatum e Glomus sp. A fase de enraizamento durou 21 dias, e após 51 e 81 dias avaliaram-se colonização micorrízica, altura, peso da matéria fresca e seca da parte aérea e relação entre raiz e parte aérea das plantas. A colonização micorrízica variou entre $50 \%$ e $70 \%$ para ambos portaenxertos, tendo efeito positivo sobre o crescimento do porta-enxerto Marubakaido, enquanto o portaenxerto M.9 teve seu desenvolvimento inibido pela presença dos FMA.
\end{abstract}

Termos para indexação: mudas, adaptação, micorriza vesículo-arbuscular, enraizamento

\section{Mycorrhizal inoculation and acclimatization of two micropropagated apple rootstocks}

\begin{abstract}
The combination of micropropagation and inoculation with arbuscular mycorrhizal fungi (AMF) can improve the quality of seedling plants produced on a commercial scale. These techniques allow high quality and homogeneous seedling production in a shorter period of time, but they require understanding of the interaction among fungi, plants, substrates, acclimatization and inoculation techniques. A study was performed under controlled conditions to develop procedures to acclimatize and inoculate AMF in two apple (Malus spp.) rootstocks: vigorous strong-rooted Marubakaido and the dwarfing, poorly rooted M.9. Micropropagated plants were treated with indole-butyric acid $(5 \mu \mathrm{M})$, and then transferred to a soil-based substrate for ex vitro rooting. The AMF were introduced before and after the rooting phase. A mixture of Scutellospora pellucida, two isolates of Glomus etunicatum, and Glomus sp. was utilized. The rooting phase lasted 21 days and plant growth was evaluated after 51 and 81 days under acclimatization conditions, for increase in height, shoot fresh and dry matter, root fresh matter, root-shoot ratio, and mycorrhizal colonization. Mycorrhizal root colonization ranged from $50 \%$ to $70 \%$ in both rootstocks. The mycorrhizal inoculation had a positive effect on root and shoot growth of Marubakaido rootstock plants, but had a negative effect on growth in M.9 plants.
\end{abstract}

Index terms: planting stock, adaptation, vesicular arbuscular mycorrhizae, rooting.

(1) Aceito para publicação em 23 de janeiro de 2001

Extraído da Dissertação de Mestrado apresentada pela primeira autora à Universidade Federal de Santa Catarina (UFSC), Florianópolis, SC.

Financiado pela Capes, Finep e pelo CNPq.

(2) UFSC, Rua Lauro Linhares, 1670, Bl. B, ap. 104, CEP 88036-002 Florianópolis, SC. E-mail: lucir@mbox1.ufsc.br

(3) UFSC, Centro de Ciências Agrárias, Dep. de Engenharia Rural, Caixa Postal 476, CEP 88040-970 Florianópolis, SC. E-mail: plovato@mbox1.ufsc.br

\section{Introdução}

A produção de plantas em escala comercial pode ser beneficiada pela obtenção de mudas de alta qualidade e homogeneidade em curtos períodos de tempo, o que pode ocorrer pelo uso da micropropagação. Nesse processo, a aclimatização é considerada uma fase crítica para o estabelecimento das plantas micropropagadas, e constitui uma etapa que pode comprometer todo o sistema de produção de 
mudas obtidas por essa técnica. Ela envolve a passagem da planta de uma condição heterotrófica (in vitro) para uma autotrófica (ex vitro), quando as plantas micropropagadas são mais suscetíveis aos estresses ambientais, devido à formação incompleta dos estômatos e ao pouco desenvolvimento da cutícula das folhas (Hooker et al., 1994). Além disso, na fase de aclimatização as plantas micropropagadas apresentam um sistema radicular incipiente ou mesmo inexistente. Entre as diversas espécies de plantas lenhosas micropropagadas, a macieira é considerada de difícil enraizamento, o que está associado a uma baixa taxa de sobrevivência em condições ex vitro. Para superar tais problemas, é adotada a técnica de se submeter a planta, simultaneamente, ao enraizamento e à aclimatização. Esse sistema, baseado na exposição das plantas micropropagadas ao ácido indolebutírico, com posterior transferência para o substrato onde ocorreram o enraizamento e a aclimatização das plantas, tem apresentado bons resultados na produção de mudas, e reduziu os custos do processo (George, 1993).

Entre as diversas vantagens que a micropropagação apresenta na produção rápida de mudas em larga escala está a eliminação de microrganismos potencialmente fitopatogênicos. No entanto, também são eliminados organismos que podem favorecer o estabelecimento das mudas micropropagadas e seu crescimento após o transplantio (Granger et al., 1983), como os fungos que formam as micorrizas arbusculares. Essas associações mutualísticas, entre certos fungos do solo e as raízes da maioria das plantas, constituem uma importante ligação entre os componentes bióticos e abióticos do solo, desempenhando papel fundamental na sobrevivência, no crescimento e desenvolvimento das plantas (Smith \& Read, 1997). As micorrizas são amplamente reconhecidas pelo efeito positivo que proporcionam no crescimento da planta, pela melhoria na absorção de nutrientes, especialmente o $\mathrm{P}$, pelo aumento do volume de solo explorado e pelo aumento da tolerância a estresses bióticos e abióticos (Gianinazzi et al., 1990; Guillemin et al., 1994).

A introdução de fungos micorrízicos arbusculares (FMA) tem um grande potencial nos programas de produção de mudas micropropagadas (Saggin Júnior \& Lovato, 1999). Além de aumentar o vigor e a capa- cidade de sobrevivência das plantas pelo aumento na absorção de nutrientes, as micorrizas podem aumentar a tolerância a patógenos radiculares e reduzir o nível de aplicação de fertilizantes (Hooker et al., 1994). Entre os benefícios que essa associação traz à produção de plantas micropropagadas destacam-se: a capacidade de saída mais precoce das condições in vitro, e redução no tempo de aclimatização (Vestberg, 1992); maior homogeneidade das plantas quanto ao crescimento (Branzanti et al., 1992) ou quanto à resposta a nutrientes (Gianinazzi et al., 1990), e maior tolerância a estresses causados por patógenos (Guillemin et al., 1994). No caso de macieira micropropagada, diversos trabalhos foram realizados para avaliar os efeitos da inoculação de FMA nessa espécie, tendo sido observados aumentos na absorção de P (Reich, 1988), no tamanho e ramificação das plantas (Taube-Baab \& Baltruschat, 1993), bem como em seu peso (Uosukainen \& Vestberg, 1994; Fortuna et al., 1996).

Os resultados da inoculação de FMA em plantas micropropagadas podem ser afetados por fatores como o momento de inoculação (in vitro ou ex vitro), a espécie vegetal, o fungo micorrízico, a composição química e física do substrato e as condições ambientais (Vestberg \& Estaún, 1994). Para obter os benefícios que a inoculação de fungos micorrízicos arbusculares pode proporcionar às plantas micropropagadas, todos estes fatores devem ser considerados, e é de fundamental importância que a associação micorrízica seja estabelecida em curto período de tempo (Saggin Júnior \& Lovato, 1999). A introdução dos FMA é geralmente feita após as raízes terem sido formadas, o que limita a época de inoculação em plantas micropropagadas a três momentos: in vitro, na fase de enraizamento; ex vitro, antes da fase de aclimatização; e ex vitro, após a aclimatização (Vestberg \& Estaún, 1994). Sendo a época de inoculação um fator crítico dentro dos programas de produção de mudas micropropagadas, o benefício para a planta, de modo geral, é maior quanto mais cedo esse procedimento ocorrer (AzcónAguilar \& Barea, 1997).

Este trabalho teve por objetivo desenvolver a combinação de técnicas de aclimatização e micorrização de mudas de porta-enxertos de macieira micropropagados, para melhorar sua capacidade produtiva. 


\section{Material e Métodos}

Foram utilizados os porta-enxertos M.9, que pertence à espécie Malus pumila (Mill) e tem origem na variedade Jaune de Metz ou French Paradise, e Marubakaido, que pertence à espécie Malus prunifolia (Willd. Borkh) de origem japonesa (Denardi, 1985). Para a produção das mudas, as bases de brotações oriundas do processo de multiplicação in vitro, tendo 4 a 5 pares de folhas e 3 a $4 \mathrm{~cm}$ de altura, foram imersas em solução com $5 \mu \mathrm{M}$ de ácido indolebutírico (AIB) por 20 segundos e transferidas para o substrato de aclimatização (Pedrotti et al., 1999).

Foram realizados dois experimentos, um para o portaenxerto Marubakaido e, outro, para o porta-enxerto M.9. Cada experimento utilizou um arranjo fatorial $2 \times 2$, composto de dois tratamentos de inoculação (inoculação micorrízica e não-micorrízica) e duas épocas de inoculação (antes e após a fase de enraizamento), com 12 repetições por tratamento, em um delineamento completamente casualizado.

Como inóculo micorrízico utilizou-se uma mistura dos seguintes fungos micorrízicos arbusculares: Scutellospora pellucida (Nicol \& Schenck) Walker \& Sanders (isolado no 2 , da coleção da UFSC), Glomus etunicatum Becker \& Gerdemann (isolado n- 6), Glomus etunicatum Becker \& Gerdemann (isolado no 8) e Glomus (Tulasne e Tulasne) sp. (isolado no 35). Os fungos haviam sido multiplicados em vasos com Paspalum notatum Flugge var. saurae Parodi ou Tagetes erecta L. Cada muda de macieira recebeu aproximadamente $1 \mathrm{~g}$ de inóculo micorrízico, constituído de solo contendo esporos, hifas e fragmentos de raízes das culturas dos fungos micorrízicos A microbiota não-micorrízica do solo foi obtida através da suspensão, em um litro de água destilada, de $100 \mathrm{~g}$ do inoculante micorrízico. Após agitação intensa, a suspensão obtida foi passada em papel-filtro com abertura de $50 \mu \mathrm{m}$, adicionando-se $1 \mathrm{~mL}$ dessa suspensão a cada uma das plantas dos tratamentos denominados não-inoculados

O substrato utilizado - uma mistura de Terra Roxa estruturada, composto termofílico e areia na proporção de 1:1:1 ( $/ \mathrm{v} / \mathrm{v})$ - foi desinfestado por 10 minutos em forno de microondas (National, modelo NE 7770KK, $2450 \mathrm{Mhz}$, $1420 \mathrm{~W}$ ) e distribuído em bandejas alveoladas com células de $120 \mathrm{~cm}^{3}$ cada. As plantas foram transferidas para as bandejas e mantidas em condições simulando túnel de aclimatização, por um período de 21 dias. Nesta fase, as plantas micropropagadas foram aclimatizadas simultaneamente à formação de raízes, sob alta umidade relativa do ar (próximo de $100 \%$ ), temperatura de $21^{\circ} \mathrm{C} \pm 3^{\circ} \mathrm{C}$, fotoperíodo de 16 horas e intensidade de radiação fotossinteticamente ativa de $73 \mu \mathrm{mol} \mathrm{m}{ }^{-2} \mathrm{~s}^{-1}$ na altura mé- dia das plantas. Após esse período, os experimentos foram conduzidos em câmara de crescimento, com temperatura de $21^{\circ} \mathrm{C} \pm 3^{\circ} \mathrm{C}$, fotoperíodo de 16 horas com radiação fotossinteticamente ativa de $120 \mu \mathrm{mol} \mathrm{m} \mathrm{m}^{-2} \mathrm{~s}^{-1}$ na altura das plantas. Todas as plantas receberam água diariamente e, semanalmente, aplicou-se $1 \mathrm{~mL}$ de solução nutritiva de Long Ashton (Resh, 1997) com 10\% da concentração original de $\mathrm{P}$.

Em cada um dos experimentos foram realizadas duas coletas de dados, a saber: a primeira, 51 dias, e a segunda, 81 dias após a saída das condições in vitro, que correspondem a 30 e 60 dias, respectivamente, após o final do período de aclimatização. Em cada coleta de dados, 12 plantas de cada tratamento foram retiradas das bandejas e tiveram as raizes cuidadosamente lavadas em água corrente e secadas em papel. A seguir, elas foram cortadas no nível do colo, e avaliou-se o peso da matéria fresca da parte aérea e das raízes. A parte aérea foi colocada em estufa a $70^{\circ} \mathrm{C}$, até peso constante, para a determinação do peso de matéria seca. As raízes foram separadas para avaliação da colonização micorrízica e análise do crescimento e desenvolvimento. Medições da altura das plantas foram realizadas ao final da fase de enraizamento e no momento da coleta, a fim de calcular o incremento em altura.

Para avaliar a colonização micorrízica das raízes, utilizou-se a técnica de Koske \& Gemma (1989): as raízes foram submetidas a descoloração em solução de hidróxido de potássio, seguida por coloração com Azul de Tripano em glicerol acidificado. Para quantificar a intensidade de colonização micorrízica, foi utilizada a técnica descrita por Trouvelot et al. (1986). Sobre uma lâmina de microscópio foram dispostos 30 segmentos de raízes com aproximadamente $1 \mathrm{~cm}$ de comprimento. A cada segmento foram auferidas notas, correspondentes à porcentagem de colonização micorrízica presente na raiz.

Os dados foram submetidos à análise de variância, através do programa STATGRAPHICS, versão 7.0, e as médias foram comparadas pelo teste de Newman-Keuls, $\mathrm{P} \leq 0,05$

\section{Resultados e Discussão}

A inoculação com FMA produziu efeitos diversos sobre o crescimento e desenvolvimento da parte aérea e do sistema radicular dos porta-enxertos micropropagados utilizados. O efeito dos tratamentos sobre o porta-enxerto Marubakaido ficou evidente 81 dias após a saída das plantas das condições in vitro (Tabela 1), quando o incremento em altura das plantas submetidas à inoculação no início 
do enraizamento apresentou tendência $(\mathrm{P}=0,053)$ a ser maior que o das plantas submetidas à inoculação em estágios tardios, ou sem o inóculo. Aos 81 dias, o peso da matéria seca da parte aérea das plantas que receberam inóculo micorrízico antes do enraizamento foi significativamente maior que o das plantas inoculadas após essa fase, ou que receberam biota não-micorrízica do solo após o enraizamento. As plantas que receberam apenas a biota não-micorrízica do solo antes do enraizamento não apresentam diferenças significativas em relação aos demais tratamentos.

O peso fresco das raízes aumentou, aos 81 dias, cerca de $60 \%$, em razão da inoculação precoce dos fungos micorrízicos arbusculares (FMA). A relação entre as massas de raiz e parte aérea (MFR/MFA) teve aumentos entre 45 e $90 \%$ da primeira para a segunda avaliação, que variaram conforme o tratamento. Na primeira avaliação, os valores da relação MFR/MFA foram similares em todos os tratamentos, enquanto na segunda avaliação houve uma tendência de plantas micorrizadas com FMA terem relações MFR/MFA maiores do que plantas não-micorrizadas. Os aumentos do crescimento do porta-enxerto Marubakaido estão de acordo com trabalhos sobre micorrização de plantas micropropagadas (Berta et al., 1995; Fortuna et al., 1996), conduzidos com plantas já enraizadas, e não com a presença dos FMA durante o enraizamento, como neste trabalho.

A colonização micorrízica atingiu valores entre $76 \%$ no tratamento micorrizado antes do enraizamento, e 20\% no tratamento micorrizado após o enraizamento (Figura 1). Na segunda avaliação, a diferença entre tratamentos diminuiu, com índices de $54 \%$ no tratamento micorrizado antes do enraizamento, e de $61 \%$ no tratamento micorrizado após essa fase. A época de introdução dos FMA no sistema de produção de mudas do porta-enxerto Marubakaido revelou-se importante, visto que as alterações foram condicionadas pelo momento da inoculação.

O porta-enxerto M.9 apresentou comportamento diferente do verificado com o Marubakaido, quando submetido a tratamento micorrízico (Tabela 2). Após 51 dias, a presença da associação micorrízica no estágio inicial do enraizamento esteve associada aos menores valores de incremento em altura, peso de matéria seca da parte aérea, peso fresco das raízes e relação MFR/MFA. As diferenças no incremento em altura e no peso da matéria seca da parte aérea mantiveram-se até o final do experimento. A relação MFR/MFA aumentou ao longo do período experimental, visto que as plantas que receberam FMA no enraizamento aumentaram a massa de raízes em três vezes, enquanto nos outros tratamentos o aumento

Tabela 1. Incremento em altura (H), massa de matéria seca de parte aérea (MSA), massa da matéria fresca de raízes (MFR) e relação MFR/MFA (massa da matéria fresca de raízes/massa da matéria fresca de parte aérea), aos 51 e 81 dias após a saída das condições in vitro, de plantas do porta-enxerto Marubakaido micropropagadas e colonizadas com fungos micorrízicos arbusculares ou com a biota não-micorrízica do solo antes ou depois da fase de enraizamento das plantas ${ }^{(1)}$.

\begin{tabular}{|c|c|c|c|c|c|}
\hline \multicolumn{2}{|c|}{ Tratamento } & \multirow[t]{2}{*}{$\mathrm{H}\left(\mathrm{cm} \mathrm{planta}^{-1}\right)$} & \multirow[t]{2}{*}{ MSA (g planta $\left.{ }^{-1}\right)$} & \multirow[t]{2}{*}{ MFR (cm planta ${ }^{-1}$ ) } & \multirow[t]{2}{*}{ MFR/MFA } \\
\hline Micorrização & Época de inoculação & & & & \\
\hline & & \multicolumn{4}{|c|}{51 dias } \\
\hline Sim & Antes & $2,47 \mathrm{a}$ & $0,132 \mathrm{a}$ & $0,279 \mathrm{a}$ & $0,700 \mathrm{a}$ \\
\hline Sim & Depois & $2,32 \mathrm{a}$ & $0,134 \mathrm{a}$ & $0,307 \mathrm{a}$ & $0,816 \mathrm{a}$ \\
\hline Não & Antes & $2,96 \mathrm{a}$ & $0,137 \mathrm{a}$ & $0,296 \mathrm{a}$ & $0,757 \mathrm{a}$ \\
\hline Não & Depois & $2,58 \mathrm{a}$ & $0,133 \mathrm{a}$ & $0,319 \mathrm{a}$ & $0,821 \mathrm{a}$ \\
\hline & & \multicolumn{4}{|c|}{81 dias } \\
\hline Sim & Antes & $3,81 \mathrm{a}$ & $0,302 \mathrm{a}$ & $0,921 \mathrm{a}$ & $1,351 \mathrm{a}$ \\
\hline Sim & Depois & $2,47 \mathrm{a}$ & $0,172 b$ & $0,559 b$ & $1,385 \mathrm{a}$ \\
\hline Não & Antes & $2,66 \mathrm{a}$ & $0,218 \mathrm{ab}$ & $0,551 b$ & $1,100 \mathrm{~b}$ \\
\hline Não & Depois & $2,51 \mathrm{a}$ & $0,191 \mathrm{~b}$ & $0,517 \mathrm{~b}$ & $1,183 \mathrm{ab}$ \\
\hline
\end{tabular}

(1)Valores seguidos de mesma letra, em cada coluna, em cada época de avaliação, não diferem significativamente entre si pelo teste de Newman-Keuls $(\mathrm{P} \leq 0,05)(\mathrm{n}=12)$. 
foi de aproximadamente duas vezes. Matsubara et al (1996) também constataram diferentes efeitos das micorrizas sobre o crescimento e desenvolvimento de parte aérea de macieira, conforme a combinação entre isolados de FMA e variedades de Malus spp.

Os índices de colonização micorrízica do portaenxerto M.9, na primeira avaliação, foram de $43 \%$ no tratamento colonizado antes do enraizamento, e de $23 \%$ no tratamento colonizado após essa fase (Figura 2). Na segunda avaliação, a diferença diminuiu: os índices foram de $56 \%$ no tratamento colonizado antes do enraizamento, e de $51 \%$ para o tratamento que recebeu o inóculo após o enraizamento. No porta-enxerto M.9, também se observou efeito significativo da época de introdução dos FMA no sistema de produção de mudas: houve reduções na

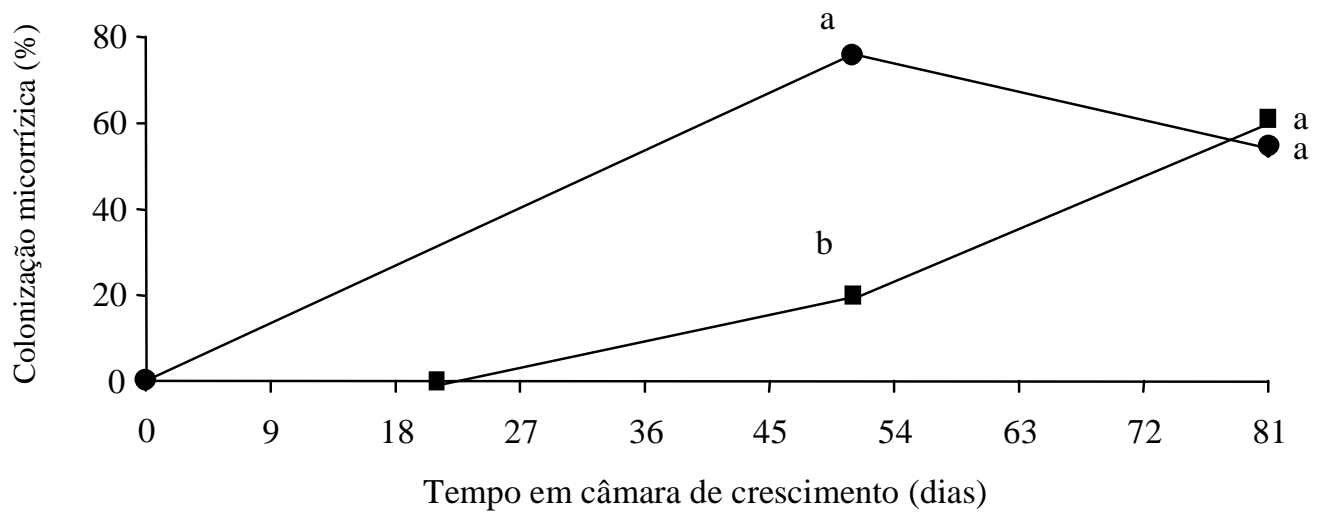

Figura 1. Intensidade da colonização micorrízica (\%) de plantas do porta-enxerto de macieira Marubakaido micropropagadas e com inoculação de fungos micorrízicos arbusculares antes e depois da fase de enraizamento das plantas. Tratamentos: M1 $(\bullet)$ : inoculação micorrízica antes da fase de enraizamento; M2 (ロ): inoculação micorrízica após a fase de enraizamento. Valores seguidos de mesma letra não diferem significativamente entre si pelo teste de Newman-Keuls $(\mathrm{p} \leq 0,05)(\mathrm{n}=12)$

Tabela 2. Incremento em altura $(\mathrm{H})$, massa de matéria seca da parte aérea (MSA), massa da matéria fresca das raízes (MFR) e relação MFR/MFA (massa da matéria fresca das raízes/massa da matéria fresca de parte aérea), aos 51 dias e 81 dias após a saída das condições in vitro, de plantas do porta-enxerto M.9 micropropagadas e colonizadas com fungos micorrízicos arbusculares ou com a biota não-micorrízica do solo, antes ou depois da fase de enraizamento das plantas ${ }^{(1)}$.

\begin{tabular}{|c|c|c|c|c|c|}
\hline \multicolumn{2}{|c|}{ Tratamento } & \multirow[t]{2}{*}{$\mathrm{H}\left(\mathrm{cm} \mathrm{planta}^{-1}\right)$} & \multirow[t]{2}{*}{ MSA (g planta $\left.{ }^{-1}\right)$} & \multirow[t]{2}{*}{$\operatorname{MFR}\left(\mathrm{cm} \mathrm{planta}^{-1}\right)$} & \multirow[t]{2}{*}{ MFR/MFA } \\
\hline Micorrização & Época de inoculação & & & & \\
\hline & & \multicolumn{4}{|c|}{51 dias } \\
\hline Sim & Antes & $3,79 b$ & $0,153 b$ & $0,187 b$ & $0,365 b$ \\
\hline Sim & Depois & $5,57 \mathrm{~b}$ & $0,266 \mathrm{ab}$ & $0,383 a$ & $0,521 \mathrm{a}$ \\
\hline Não & Antes & $5,85 \mathrm{~b}$ & $0,272 \mathrm{ab}$ & $0,386 \mathrm{a}$ & $0,483 \mathrm{a}$ \\
\hline Não & Depois & $8,82 \mathrm{a}$ & $0,366 \mathrm{a}$ & $0,559 \mathrm{a}$ & $0,512 \mathrm{a}$ \\
\hline & & \multicolumn{4}{|c|}{81 dias } \\
\hline Sim & Antes & $4,44 \mathrm{~b}$ & $0,238 b$ & $0,712 \mathrm{a}$ & $1,100 \mathrm{a}$ \\
\hline Sim & Depois & $5,89 \mathrm{~b}$ & $0,310 \mathrm{ab}$ & $0,870 \mathrm{a}$ & $1,088 \mathrm{a}$ \\
\hline Não & Antes & $5,53 \mathrm{~b}$ & $0,308 \mathrm{ab}$ & $0,820 \mathrm{a}$ & $1,052 \mathrm{a}$ \\
\hline Não & Depois & $8,19 \mathrm{a}$ & $0,395 \mathrm{a}$ & $1,060 \mathrm{a}$ & $1,117 \mathrm{a}$ \\
\hline
\end{tabular}

${ }^{(1)}$ Valores seguidos de mesma letra, em cada coluna, em cada época de avaliação, não diferem significativamente entre si pelo teste de Newman-Keuls $(\mathrm{P} \leq 0,05)(\mathrm{n}=12)$. 
massa de raízes e da parte aérea quando a inoculação micorrízica ocorreu antes do enraizamento.

Nas condições deste experimento e no período avaliado, os FMA parecem ter se constituído em dreno de energia nas plantas de M.9, com reflexos negativos no crescimento delas. Isso aponta para a necessidade de seleção de isolados de FMA e de outras épocas para a sua introdução na aclimatização deste porta-enxerto. O efeito de diminuição na massa do sistema radicular do porta-enxerto M.9 desapareceu ao longo do período experimental. Isto indica que as alterações ocorridas, além de temporárias, foram resultado de interações com outras variáveis, como os níveis de hormônios endógenos das plantas.

Nos dois porta-enxertos, os efeitos da presença dos FMA foram maiores quando a inoculação ocorreu logo após a aplicação de ácido indolebutírico (AIB). As plantas ainda deveriam ter, em seus tecidos, níveis altos de auxina exógena ou de seus metabólitos, e a interação entre colonização micorrízica e aplicação exógena de AIB já foi demonstrada em porta-enxertos de citros (Dutra et al., 1996). As observações no presente trabalho abrem perspectivas para estudos relacionados ao efeito de hormônios aplicados sobre o crescimento e desenvolvimento das plantas associadas a FMA.
A resposta aos FMA também variou segundo o genótipo vegetal: a associação micorrízica aumentou a produção de raízes do porta-enxerto Marubakaido, mais vigoroso e com sistema radicular mais desenvolvido, e teve um efeito inibidor sobre o desenvolvimento do M.9, nanizante e com sistema radicular menos desenvolvido.

A melhor época para a inoculação dos FMA em muitas espécies de plantas micropropagadas é o início da aclimatização, quando as plantas têm apenas primórdios radiculares (Branzanti et al., 1992); mas algumas plantas se desenvolvem melhor quando a inoculação ocorre após a aclimatização. Na macieira, trabalhos recomendam a inoculação antes (Branzanti et al., 1992) ou após (Uosukainen \& Vestberg, 1994) a aclimatização; e os resultados deste trabalho confirmam que em cada espécie vegetal há uma combinação específica de fungo micorrízico, substrato e época de inoculação. A presença da associação micorrízica na fase inicial do enraizamento do porta-enxerto Marubakaido mostrou potencial de utilização na produção de mudas vigorosas, com melhor estabelecimento em viveiro ou a campo. Contudo, novos protocolos de inoculação precisam ser estabelecidos no M.9, iniciando-se pela seleção de outros isolados de FMA, visto que a mistura utilizada foi prejudicial ao crescimento deste porta-en-

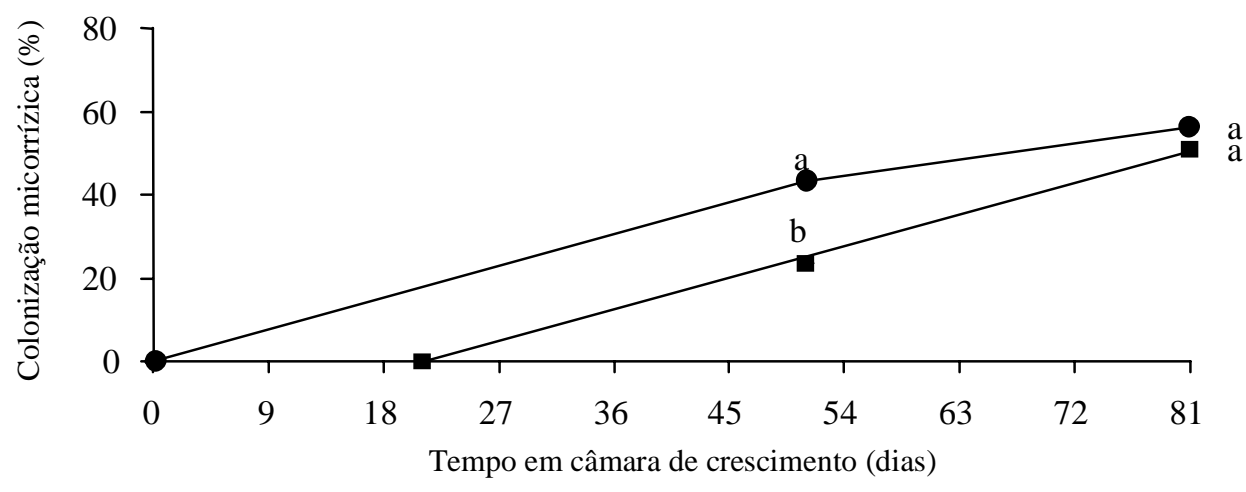

Figura 2. Intensidade de colonização micorrízica (\%) de plantas do porta-enxerto de macieira M.9 micropropagadas e com inoculação de fungos micorrízicos arbusculares antes e depois da fase de enraizamento das plantas. Tratamentos: M1 $(\bullet)$ : inoculação micorrízica antes da fase de enraizamento; M2 (匹): inoculação micorrízica após a fase de enraizamento. Valores seguidos de mesma letra não diferem significativamente entre si pelo teste de Newman-Keuls $(p \leq 0,05)(n=12)$. 
xerto. Outra possibilidade de utilização desses fungos mutualistas em plantas do porta-enxerto M.9 é a inoculação mais tardia, na fase de viveiro.

A utilização de uma mistura de FMA como inoculante não garantiu eficiência em todas as situações propostas no presente trabalho. A especificidade entre fungo e planta não existe nas micorrizas arbusculares, mas as diferenças entre isolados de fungos na promoção do crescimento e do desenvolvimento de uma mesma espécie são interpretadas como especificidade funcional (Fortuna et al., 1996). Neste trabalho é possível que isolados de FMA menos eficientes em promover o crescimento das plantas tenham sido mais competitivos para colonizar as raízes nas condições em que o porta-enxerto M.9 se desenvolveu. A biota não-micorrízica do solo teve efeito sobre o crescimento e o desenvolvimento dos portaenxertos: os que receberam adição da biota do solo antes da fase de enraizamento apresentaram comportamento similar ao das plantas que receberam a inoculação micorrízica após o enraizamento. Isso indica que outros microrganismos do solo têm efeito sobre o desenvolvimento dos porta-enxertos, e podem afetar seu crescimento e desenvolvimento.

Os efeitos verificados no crescimento do sistema radicular dos porta-enxertos conduzem à recomendação de que se investiguem as implicações dessas modificações associadas à presença dos FMA e dos outros microrganismos do solo. A possibilidade de manipular os FMA em combinação com outros microrganismos do solo depende do melhor entendimento das relações entre eles, e da seleção dos isolados a serem utilizados. Mediante estudos específicos será possível obter informações sobre as condições em que os FMA tenham sinergia com outros microrganismos do solo (Andrade et al., 1998). Desta forma, a inoculação de FMA juntamente com outros microrganismos poderá assegurar o estabelecimento das micorrizas e aumentar os benefícios dessa associação. Deve-se verificar, ainda, o efeito da aplicação de diversas concentrações de auxina e a presença de FMA, e desenvolver estudos que verifiquem o efeito da biota não-micorrízica do solo sobre o crescimento e desenvolvimento dos portaenxertos. O melhor entendimento desses efeitos poderá contribuir para o fornecimento, ao produtor, não só de plantas, mas também de uma comunidade em cuja rizosfera haja microrganismos que atuem na nutrição e na proteção contra estresses bióticos e abióticos. O protocolo de enraizamento, aclimatização e inoculação de FMA abordado no presente trabalho, apesar dos resultados obtidos com o porta-enxerto M.9, é promissor, e não está limitado simplesmente a macieiras. Ele pode ser adaptado a outras culturas de interesse das empresas ou viveiristas, e contribuir para que se produzam mudas com alta qualidade e homogeneidade, em curtos períodos de tempo.

\section{Conclusões}

1. A inoculação da mistura de isolados de fungos micorrízicos arbusculares aumenta o desenvolvimento das partes aérea e radicular do porta-enxerto Marubakaido, e esse efeito é mais acentuado quando a inoculação é realizada antes da fase de enraizamento.

2. A inoculação dos mesmos isolados de fungos micorrízicos arbusculares reduz o desenvolvimento de parte aérea e radicular do porta-enxerto M.9, e esse efeito é mais acentuado quando a inoculação é realizada antes da fase de enraizamento.

\section{Referências}

ANDRADE, G.; LINDERMAN, R. G; BETHLENFALVAY, G. J. Bacterial associations with mycorrhizosphere and hyphosphere of the arbuscular mycorrhizal fungus Glomus mosseae. Plant and Soil, Dordrecht, v. 202, p. 78-87, 1998.

AZCÓN-AGUILAR, C.; BAREA, J. M. Applying mycorrhiza biotechnology to horticulture: significance and potentials. Scientia Horticulturae, Amsterdam, v. 68, n. 4, p. 24, 1997

BERTA, G.; TROTTA, A.; FUSCONI, A.; HOOKER, J. E.; MUNRO, M.; ATKINSON, D.; GIOVANETTI, M.; MORINI, S.; FORTUNA, P.; TISSERANT, B.; GIANINAZZI-PEARSON, V; GIANINAZZI, S. Arbuscular mycorrhizal induced changes to plant growth and root system morphology in Prunus cerasifera L. Tree Physiology, Victoria, v. 15, p. 281-293, 1995.

Pesq. agropec. bras., Brasília, v. 37, n. 2, p. 177-184, fev. 2002 
BRANZANTI, B.; GIANINAZZI-PEARSON, V.; GIANINAZZI, S. Influence of phosphate fertilization on the growth and nutrient status of micropropagated apple infected with endomycorrhizal fungi during the weaning stage. Agronomie, Paris, v. 12, p. 841-845, 1992

DENARDI, F. Porta-Enxertos. In: EMPRESA CATARINENSE DE PESQUISA AGROPECUÁRIA (Florianópolis, SC). Manual da cultura da macieira. Florianópolis, 1985. p. 92-132

DUTRA, P. V.; ABAD, M.; ALMELA, V.; AGUSTÍ, M. Auxin interaction of the vesicular arbuscular mycorrhizal fungus Glomus intraradices Schenck Smith improves vegetative growth of two citrus rootstocks. Scientia Horticulturae, Amsterdam, v. 66, p. 77-83, 1996.

FORTUNA, P.; CITERNESI, A. S.; MORINI, S. A. O.; VITAGLIANO, C.; GIOVANNETTI, M. Influence of arbuscular mycorrhizae and phosphate on shoot apical growth of micropropagated apple and plum rootstocks. New Phytologist, Cambridge, Inglaterra, v. 16, p. 757-763, 1996.

GEORGE, E. F. Plant propagation by tissue culture the technology. 2. ed. Edington: Exegetics, 1993. Part 1

GIANINAZZI, S.; TROUVELOT, A.; GIANINAZZIPEARSON, V. Conceptual approaches for the rational use of VA endomycorrhizae in agriculture: possibilities and limitations. Agriculture, Ecosystems and Environment, Amsterdam, v. 29, n. 14, p. 153-161, 1990.

GRANGER, R. L; PLENCHETTE, C.; FORTIN, J A Effects of a vesicular arbuscular (VA) endomycorrhizal fungus (Glomus epigaeum) on the growth and leaf mineral content of two apple clones propagated in vitro. Canadian Journal of Plant Science, Ottawa, v. 63, p. 551-555, 1983.

GUILLEMIN, J. P.; GIANINAZZI, S.; GIANINAZZIPEARSON, V.; MARCHAL, J. Contribution of endomycorrhizas to biological protection of micropropagated pineapple (Annanas comosus (L.) Merr) against Phytophtora cinnamomi Rands. Agricultural Science in Finland, Helsinki, v. 3, p. 241-251, 1994

HOOKER, J. E.; GIANINAZZI, S.; VESTBERG, M.; BAREA, J. M.; ATKINSON, D. The application of arbuscular mycorrhizal fungi to micropropagation systems - an opportunity to reduce chemical inputs. Agricultural Science in Finland, Helsinki, v. 3, n. 3, p. 227-232, 1994

KOSKE, R. E.; GEMMA, J. N. A modified procedure for staining roots to detect VA mycorrhizas. Mycological Research, Cambridge, Inglaterra, v. 92, n. 4, p. 486-505, 1989.

MATSUBARA, Y.; KARIKOMI, T.; IKUTA, M.; HORI, H.; ISHIKAWA, S.; HARADA, T. Effects of arbuscular mycorrhizal fungus inoculation on growth of apple (Malus ssp.) seedlings. Journal of the Japanese Society for Horticultural Science, Tokyo, v. 65, n. 2, p. 297-302, 1996.

PEDROTTI, E. L.; VOLTOLINI, J. A.; MACIEL, S. C. Porta-enxertos de macieira: enraizamento ex vitro e aclimatização de plantas produzidas in vitro. Revista Agropecuária Catarinense, Florianópolis, v. 12, n. 4, p. 32-34, dez. 1999

REICH, L. Rates of infection and effects of five vesiculararbuscular mycorrhizal fungi on apple. Canadian Journal of Plant Science, Ottawa, v. 68, p. 233-239, 1988.

RESH, H. M. Cultivos hidropónicos: nuevas técnicas de producción. 4. ed. MundiPrensa Libros, 1997. 509 p

SAGGIN JÚNIOR, O.; LOVATO, P. E. Aplicação de micorrizas arbusculares: mudas e plantas micropropagadas. In: SIQUEIRA, J. O.; MOREIRA, F. M. S.; LOPES, A. S.; GUILHERME, L. R. G.; FAQUIN, V; FURTINI NETO, A. E.; CARVALHO, J. G. (Ed.). Interrelações biologiafertilidade do solo. Viçosa, MG: Sociedade Brasileira de Ciência do Solo, 1999. p. 725-773.

SMITH, S. E.; READ, D. J. Mycorrhizal symbiosis 2. ed. San Diego: Academic, 1997. 605 p

TAUBE-BAAB, H.; BALTRUSCHAT, H. Effects of vesicular arbuscular mycorrhizal fungi on the growth of young apple trees in apple replant disease soil. Journal of Plant Disease and Protection, Stuttgart, v. 100, n. 5, p. 474-481, 1993

TROUVELOT, A.; KOUGH, J. L.; GIANINAZZIPEARSON, V. Mesure du taux de mycorhization VA d'un sistème radiculaire: recherche de méthodes d'estimation ayant une signification fonctionnelle. In: GIANINAZZI, S.; GIANINAZZI-PEARSON, V. (Ed.). Mycorhizes: physiologie et genétique. Dijon: Inra, 1986. p. 217-220.

UOSUKAINEN, M.; VESTBERG, M. Effect of inoculation with arbuscular mycorrhizas on rooting, weaning and subsequent growth of micropropagated Malus (L.) Moench. Agricultural Science in Finland, Helsinki, v. 3, p. 269-279, 1994.

VESTBERG, M. Arbuscular mycorrhizal inoculation of micropropagated strawberry and field observations in Finland. Agronomie, Paris, v. 12, p. 865-867, 1992.

VESTBERG, M.; ESTAÚN, V. Micropropagated plants: an opportunity to positively manage mycorrhizal activities. In: GIANINAZZI, S.; SCHÜEPP, H. (Ed.). Impact of arbuscular mycorrhizas on sustainable agriculture and natural ecosystems. Basel: Birkhäuser, 1994. p. 217-226. 